\title{
(IN)SUBORDINAÇÕES CURRICULARES: “DESACELEREM O MUNDO QUE EU QUERO DESCER”*
}

\author{
Eliana Póvoas Pereira Estrela Brito ${ }^{1}$
}

\begin{abstract}
RESUMO: Este artigo operacionaliza conceitos presentes na filosofia da diferença - Foucault, Deleuze, Guattari, Pelbart, Lazzarato, entre outros - para analisar os discursos que circulam na mídia digital endereçados aos( $\boldsymbol{a} \boldsymbol{s})$ profissionais da educação, pais e estudantes com objetivo de fomentar o debate acerca da educação em tempos de pandemia da Covid-19. Por um lado, mostra-se a exacerbação dos redimensionamentos sofridos nas noções de tempo e de espaço na contemporaneidade. Por outro, aponta-se para a manutenção dos fundamentos da modernidade nas orientações destinadas à escola e seus currículos. Este artigo defende, então, que este tempo de suspensão das rotinas escolares possa intensificar a educação para a potência em detrimento da obediência.
\end{abstract}

Palavras- chave: Escola. Currículo. Mídia. Tempo/espaço.

\section{CURRICULAR (IN)SUBORDINATIONS: 'STOP THE WORLD 'CAUSE I WANNA GET OFF'}

\begin{abstract}
This article operationalizes concepts of the philosophy of difference Foucault, Deleuze, Guattari, Pelbart, Lazzarato and so on - in order to analyze the discourses that circulate in the digital media addressed to education professionals, parents, and students, thus promoting a debate about education in times of Covid-19 pandemic. On the one hand, it shows the exacerbation of the resizing in the notions of time and space in contemporary times. On the other hand, it points to the maintenance of the foundations of modernity in the guidelines for schools and their curricula. Therefore, the article argues that this period of suspension from school routines can intensify education for power at the expense of obedience.
\end{abstract}

Keywords: School. Curriculum. Media. Time/space.

\footnotetext{
${ }^{\star}$ Depoimento de uma professora para a reportagem "Prática Docente: 30 Depoimentos sobre como a Escola foi Recebida em Casa". Disponível em: https://desafiosdaeducacao.grupoa.com.br/depoimentos-sobre-escola-em-casa/. Acesso em:4 maio 2020.

1.Universidade Federal do Sul da Bahia - Instituto de Humanidades, Artes e Ciências - Programa de Pós-graduação em Estado e Sociedade/Programa de Pós-graduação em Ensino e Relações Étnico-raciais - Itabuna (BA), Brasil. E-mail: epovoas@ufsb.edu.br Editor de Seção: Pedro Goergen
} 


\title{
(IN)SUBORDINACIONES CURRICULARES: “DETENGAN EL MUNDO QUE QUIERO BAJAR"
}

\begin{abstract}
RESUMEN: Este artículo operacionaliza conceptos presentes en la filosofía de la diferencia - Foucault, Deleuze, Guattari, Pelbart, Lazzarato, entre otros - para analizar los discursos que circulan en los medios digitales dirigidos a los(as) profesionales de la educación, padres y estudiantes con el objetivo de fomentar el debate sobre la educación en tiempos de pandemia de Covid-19. Por un lado, se muestra la exacerbación de los redimensionamientos sufridos en las nociones de tiempo y espacio contemporáneas. Por otra parte, se apunta hacia el mantenimiento de los fundamentos de la modernidad en las orientaciones destinadas a la escuela y sus currículos. Este artículo defiende, entonces, que este tiempo de suspensión de las rutinas escolares pueda intensificar la educación para la potencia en detrimento de la obediencia.
\end{abstract}

Palabras clave: Escuela. Currículo. Media. Tiempo/espacio.

\section{Introdução}

\begin{abstract}
A floresta está viva. Só vai morrer se os brancos insistirem em destrui-la. Se conseguirem, os rios vão desaparecer debaixo da terra, o chão vai se desfazer, as árvores vão murchar e as pedras vão rachar no calor. A terra ressecada ficará vazia e silenciosa. Os espíritos xapiri, que descem das montanhas para brincar na floresta em seus espelhos, fugirão para muito longe. Seus pais, os xamãs, não poderão mais chamá-los e fazê-los dançar para nos proteger. Não serão capazes de espantar as fumaças de epidemia que nos devoram. Não conseguirão mais conter os seres maléficos, que transformarão a floresta num caos. Então morreremos, um atrás do outro, tanto os brancos quanto nós. Todos os xamãs vão acabar morrendo. Quando não houver mais nenhum deles vivo para sustentar o céu, ele vai desabar (KOPENAWA; ALBERT, 2015).
\end{abstract}

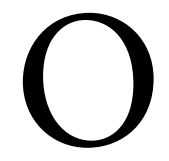

depoimento do xamã Davi Kopenawa, epígrafe do livro A Queda do Céu: Palavras de um Xamã Yanomami (KOPENAWA; ALBERT, 2015), parece anunciar de forma profética o estonteante cenário social marcado pela insurgência da grave crise sanitária, econômica, cultural e política desencadeada pela pandemia da Covid-19 e seus perturbadores efeitos globais. Uma espécie de força-tarefa intelectual agenciou um conjunto de reflexões e expandiu redes de sociabilidade, constituindo uma polifonia de vozes sem precedentes. Entre a asfixia, "esse é um vírus que afeta nossa capacidade de respirar [...]" (MBEMBE, 2020), e o desejo de fuga, brechas foram abertas para que a vida no planeta e seu futuro passassem a ser pensados sob a égide do "novo normal", cuja racionalidade encontra-se sob rasura pelo declínio dos fundamentos da modernidade e suas crenças na razão universal, no conhecimento único e verdadeiro e no sujeito do Iluminismo. Há uma percepção de asfixia social que contagia o mundo, agora, em suspensão.

Uma ideia de fôlego pode ser extraída do pensamento de Ailton Krenak (2019), quando nos propõe ideias para adiar o fim do mundo - antecipando o conturbado acontecimento da Covid-19 - ao revisitar a tradição xamã yanomami para argumentar que o nosso tempo é especialista em criar ausências, esvaziando o próprio sentido da experiência da vida. A alegria manifesta em práticas simples, presentes nas culturas dos povos originários, como cantar, dançar e festejar a própria existência, gera intolerância social e política, 
na medida em que remete a uma outra economia nas relações de poder e uma lógica diferente nas relações sociais; enfim, a um modo distinto de existir e de coexistir no mundo.

Seguindo os ensinamentos dos povos da floresta, Krenak (2019) argumenta que esse desconforto contemporâneo, manifesto pela sensação de que o céu está ficando muito baixo, prestes a desabar, dá-se em resposta a um desequilíbrio ocasionado entre a lógica predatória do mercado e as forças da natureza. Na perspectiva yanomami, são os xapiris, espírito das florestas, os responsáveis por sustentar o céu e, por consequência, a morte dos seres da floresta tornará inevitável a queda do céu. Para o autor, "suspender o céu é ampliar o nosso horizonte; não o horizonte prospectivo, mas um existencial", e nos convida a pensar o "espaço não como um lugar confinado, mas como o cosmos onde a gente pode despencar em paraquedas coloridos” (KRENAK, 2019, p. 15).

Não por acaso recorremos aqui à tradição dos povos da floresta! Em tempos pandêmicos, tomados pelo medo e pela insegurança generalizados, por um lado, sentimos-nos imobilizados e, por outro, em estado permanente de vertigem. Embora, hipoteticamente "suspensos", não são desprezíveis os movimentos acelerados do neoliberalismo e suas capturas maquínicas sobre cada um(a) de nós. Enquanto as pessoas adoecem, sofrem, morrem, ironicamente a sociedade passa a ter à disposição um fast-food de lives para todos os tipos e para os mais variados gostos e necessidades do momento.

Na realidade brasileira, enquanto as ciências buscam, obstinadamente, um antídoto ao vírus, as atuais políticas neoliberais de cunho racista e elitista colocam a vida das pessoas pobres, negras, indígenas e moradoras das periferias, em situação de mais vulnerabilidade comparativamente às pessoas brancas, residentes em centros urbanos e pertencentes às classes médias e altas. A taxa de mortalidade de pessoas negras pela Covid-19 é 60\% maior à de pessoas brancas. Mesmo diante dos fatos, o governo brasileiro insiste em potencializar a lógica do "necroliberalismo", sacrificando o que pode ser descartado, o que não possui valor de mercado e que, invariavelmente, "afeta as mesmas raças, as mesmas classes sociais e os mesmos gêneros" (MBEMBE, 2020).

Essas questões atravessam por inteiro o campo da educação, em geral, e trazem interferências significativas para a educação escolarizada pública, em particular. De acordo com uma das pesquisas realizadas sobre a situação dos professores no Brasil durante a pandemia, ${ }^{1} 66 \%$ dos professores pesquisados afirmaram que, por motivos de saúde, já precisaram se afastar do trabalho. Entre os problemas de saúde mais relatados, encontram-se: estresse e dor de cabeça (63\%), insônia (39\%), dores corporais (38\%) e alergias (38\%). Além disso, $68 \%$ dos profissionais afirmaram já ter sofrido crises de ansiedade, $28 \%$ deles tendo entrado em estado de depressão.

Embora o adoecimento psíquico em professores brasileiros venha constituindo temática com crescente relevância científica, atravessando diversos campos de saber, o fato é que, para além dos graves problemas enfrentados pela avassaladora desigualdade de acesso às tecnologias digitais de informação e comunicação, suscitadas pela utilização do chamado Ensino Remoto Emergencial (ERE), a pandemia da Covid-19 colocou em xeque um conjunto de premissas que estruturam o campo da educação, entendidas como universais. Supomos que a construção dos "paraquedas coloridos", conforme nos sugere Krenak (2019), passe pela possibilidade de colocarmos sob suspeita essas proposições e, para essa tarefa, mobilizamos, em especial, as noções de tempo/espaço que orientam e estruturam os modos pelos quais a escola e seus currículos encontram-se configurados nas escolas públicas da educação básica. Questionamos: a pandemia poderá vir a ser um acontecimento que potencialize uma concepção de escola e de currículo que resista aos imperativos dos modos de produção ultraneoliberais e suas capturas sobre nossos corpos e sonhos?

Para tanto, constituímos como corpus da pesquisa os discursos que circulam na mídia digital, endereçadosaos(às) profissionaisdaeducação, paiseestudantes, comoobjetivodeinformaresubsidiar/contribuir 
com o debate acerca da educação nos tempos da crise sanitária, econômica e política que assola o Brasil nos dias de hoje. Não estabelecemos diferenciações entre os gêneros textuais (reportagens, notícias, depoimentos, textos legais), pois seguimos a compreensão de Foucault e consideramos os discursos "como um conjunto de enunciados que se apoiam numa mesma formação discursiva” (FOUCAULT, 1986, p. 135). Para a leitura desses discursos, acionamos alguns conceitos presentes na filosofia da diferença, a partir de autores como Foucault, Deleuze, Guattari, Pelbart, Lazzarato, entre outros.

Este artigo está organizado da seguinte maneira: inicialmente, são problematizadas as funções sociais da escola na modernidade. Acompanham-se as condições históricas que possibilitaram que, ao longo de sua trajetória, diferentes significados sociais, políticos e econômicos fossem atribuídos à escola. A seguir, discutem-se as noções de tempo e espaço - conceitos basilares para a organização do currículo e das rotinas escolares -, buscando compreender seus redimensionamentos diante do acontecimento da Covid-19. Por fim, trabalha-se a noção de currículo como agenciamento, na perspectiva de Deleuze, buscando mapear os sentidos que esses discursos atribuem ao currículo e como eles constroem os sujeitos professores e professoras da educação básica brasileira. Fechamos o texto retornando às questões por ele suscitadas e argumentando que, apesar de toda a ofensiva neoliberal que vem sendo direcionada para a educação pública no Brasil, somos inventivos(as) o suficiente para construir paraquedas coloridos e amortizar sua inevitável queda, se essa condição for inevitável.

\section{Escola: Discursos Circulantes}

Se a escola (scholé) da tradição grega clássica era o lugar do ócio e do tempo livre, destinada aos meninos das elites gregas da época, a modernidade vê emergir uma outra concepção de escola, forjada, em especial, pelos saberes das ciências modernas e da ascensão e do fortalecimento da burguesia. Essa reconfiguração dos saberes contribuiu decisivamente para o surgimento de uma nova concepção de infância, afastando-a progressivamente do mundo dos adultos. A emergência de um novo estatuto para a infância, ao mesmo tempo em que institui um processo de diferenciação entre o mundo das crianças e o mundo dos adultos, destitui a educação comunitária e a liberdade de costumes como modos de educar as crianças. Por efeito, postula-se a necessidade de que haja espaços específicos destinados à educação das crianças, sob a responsabilidade de sujeitos autorizados e expertos, como forma de "isolar cada vez mais as crianças durante um período de formação tanto moral como intelectual, de 'adestrá-las' graças a uma disciplina mais autoritária, e, desse modo, separá-las da sociedade dos adultos" (ARIÈS, 1986, p. 165).

Trabalhando sobre a montagem de peças, engates, funções e modos de funcionamento da "maquinaria escolar" (VARELA; ALVAREZ-URÍA, 1992), ficamos conhecendo as possibilidades da institucionalização da escola pública, gratuita e obrigatória como um dos dispositivos de poder disciplinar. Utilizando-se de uma perspectiva genealógica e acompanhando os estudos foucaultianos, esses autores mostram que o nascimento da escola moderna como lugar de passagem obrigatória para as crianças das classes populares é correlata à entrada de uma nova forma de atuação do poder disciplinar.

É importante sublinhar que a disciplina é uma técnica, um dispositivo de poder, que se exerce em rede e atravessa uma série de espaços sociais, entre os quais a escola. Ao funcionar em rede, a disciplina não limita seus exercícios a determinadas dimensões institucionais. Antes atravessa todo um conjunto de práticas e disposições arquitetônicas, o que implica dizer que a escola, o currículo e as práticas pedagógicas são investidos pelo poder disciplinar. Isso, a um só tempo, "aumenta as forças do corpo (em termos econômicos de utilidade) e diminui essas mesmas forças (em termos políticos de obediência)" (FOUCAULT, 2013a, p. 46). 
Embora as sociedades disciplinares tenham tido seu maior desempenho no século XX, respondendo às demandas do modo de produção fordista, o fato é que as escolas ainda mantêm um regime disciplinar em seus cotidianos: a vigilância hierárquica, mantida por professores em sala de aula, atravessa os diferentes espaços/tempos escolares para serem exercidas pelos olhares atentos dos(as) chefes de disciplina nos corredores e pátios, chegando à sua forma mais ostensiva nas chamadas escolas cívico-militares. A sanção normalizadora (castigos e punições, agora mais simbólicos do que corporais), outra técnica colocada à disposição pelas disciplinas, permanece vigorosa nos sistemas escolares. Ela é exercida para que todo e qualquer desvio de comportamento, de atitudes e de formas de estar e conviver na escola seja punido, chamado à atenção e considerado anormal. A norma atua no lugar da lei e tem por finalidade regular/normalizar os sujeitos escolares em conformidade com os princípios disciplinares. O exame (a prova), como dispositivo que evidencia as relações entre saber e poder, ao mesmo tempo em que classifica, hierarquiza e separa os sujeitos escolares, s qualifica-os entre bons e maus alunos: atenciosos, desatentos, assíduos, infrequentes, esforçados, displicentes, normais e anormais.

$\mathrm{Na}$ esteira dos estudos foucaultianos, Varela vai argumentar que "os saberes pedagógicos são o resultado, em boa parte, da articulação dos processos que levaram à pedagogização dos conhecimentos e à disciplinarização interna dos saberes" (1994, p. 93). A instauração dessa nova ordem dos saberes se deve, muito especialmente, aos movimentos realizados pelo Estado, direcionados ao governo dos sujeitos e das populações e ao fortalecimento das forças produtivas. Subsidiado pelos ensinamentos do campo da economia política (que passa a ocupar o lugar antes concedido à análise das riquezas), inicia-se um processo de disciplinamento dos saberes múltiplos, diversos e heterogêneos. Esse tipo de racionalidade, que passa a presidir a modernidade - as sociedades disciplinares, como Foucault propôs -, não tem suas funções apenas direcionadas para os modos de produção. Ao constituir um tipo de lógica que circula e organiza diversos tempos/espaços sociais, a disciplina "modela" as diferentes instituições sociais criadas na modernidade, como presídios, hospitais, asilos e escolas.

Assim, a disciplina é exercida na organização dos espaços. Distribui os sujeitos em espaços, individualiza os corpos. "Cada indivíduo no seu lugar; e em cada lugar, um indivíduo" (FOUCAULT, 2013b, p. 138) busca evitar aglomerações, controlar movimentos desordenados, marcar presenças e ausências, estabelecer séries e hierarquizar espaços e sujeitos. A disciplina organiza o tempo. O tempo demarcado para trabalhar, para estudar, para o lazer etc. constitui uma das formas de sujeição do corpo, visando extrair o máximo de suas forças e de sua produtividade. Esses tempos/espaços fabricados pela disciplina são mantidos sob vigilância constante com a finalidade de controlar as atividades realizadas, localizar, delimitar, expandir, restringir e interditar movimentos possíveis. É preciso maximizar forças, tornar, a um só tempo, o corpo dócil e útil aos modos de produção capitalista. Para tanto, a disciplina requer um registro sistemático dos conhecimentos, de modo a correlacionar saber-poder.

Aprendemos que "a história tem por função mostrar que aquilo que é nem sempre foi, isto é, que é sempre na confluência de encontros, acasos, ao longo de uma história frágil, precária, que se formaram as coisas que nos dão a impressão de serem as mais evidentes" (FOUCAULT, 1994, p. 448). Distante de um entendimento de história linear, cronológica e evolutiva, Deleuze deixa-nos, como post-scriptum, o anúncio de que "as sociedades disciplinares é o que já não éramos mais, o que deixávamos de ser" (1992, p. 219). Vivemos, segundo Deleuze, sob a égide das sociedades do controle.

Agora, já não há mais a necessidade de confinar os sujeitos em espaços fechados. Ao contrário, os próprios espaços de confinamento vivem uma situação agonizante, na medida em que já não cumprem mais seus objetivos políticos. O capitalismo, que nas sociedades disciplinares era voltado à produção e exigia corpos obedientes, dóceis e uteis para esse modo de produção, hoje é o capitalismo de sobre-produção. “Já não é um 
capitalismo dirigido para a produção, mas para o produto, isto é, para a venda ou para o mercado. Por isso ele é essencialmente dispersivo, e a fábrica cedeu lugar à empresa” (DELEUZE, 1992, p. 221).

O capitalismo de sobre-produção se exerce por modelagens. Não estamos mais diante do par massa-indivíduo. Os indivíduos tornaram-se "dividuais", divisíveis, e as massas tornaram-se amostras, dados, mercados ou "bancos" (DELEUZE, 1992, p. 222). O modus operandi é o da empresa, o sujeito flexível, inovador e criativo é o empresário de si, sempre disposto a ter que se qualificar, acompanhar as "tendências", surfar nas ondas dos incontáveis cursos e programas de reciclagens e atualizações, exigindo sempre formações permanentes. Assim, o marketing constitui importante dispositivo de controle.

Pensar a escola pública brasileira na contemporaneidade a partir do prognóstico de que os meios de confinamento agonizam e de que "trata-se apenas de gerir sua agonia e ocupar as pessoas, até a instalação das novas forças” (DELEUZE, 1992, p. 223) não requer de nós nenhum esforço imaginativo. A escola pública tem sido percebida como um lugar de difícil convivência (desinteresse, desmotivação, discriminação, violência, etc.) para uma vasta maioria de estudantes e profissionais da educação. Basta lembrar aqui que o Brasil ocupa o primeiro lugar no ranking de violência em escolas, em conformidade com dados levantados pela Organização para a Cooperação e Desenvolvimento Econômico (OCDE), em âmbito mundial. ${ }^{2}$

No entanto, diante do acontecimento ${ }^{3}$ da Covid-19, cabe perguntar, parafraseando Krenak (2019), por que insistimos tanto e durante tanto tempo em participar dessa lógica que se impõe à escola e aos sujeitos da educação, bem como legitimá-la, sendo que, na maioria das vezes, ela só limita a nossa capacidade de invenção, criação, existência e liberdade? Não seria a pandemia um acontecimento importante para que pudéssemos repensar a escola e seu currículo a partir da perspectiva da alegria, do encontro, da experiência?

\section{"Quando as Aulas Voltarem eu Não Quero que Tenha 'Aula"'4}

Tem sido crescente o número de reportagens e textos que circulam nas diferentes mídias discutindo a chamada educação pós-pandemia. Nesse conjunto discursivo, as preocupações com o possível retorno das atividades presenciais nas escolas das redes públicas e com seus protocolos de segurança, bem como com o bem-estar das pessoas que, direta ou indiretamente, estão sofrendo as consequências da suspensão das aulas, têm sido a tônica. Embora o discurso sobre os cuidados de si e dos outros (em especial, da família) esteja fortemente disseminado nessa discursividade, as "dicas" voltadas à superação da ansiedade, do medo, da angústia e do estresse por parte dos profissionais da educação passam pela necessidade de ter um planejamento no qual a organização do tempo e do espaço destinados aos processos de ensinoaprendizagens deva estar bem delineada. Nessa direção, uma das reportagens adverte que "o tempo que a criança tem disponível para o ensino remoto é diferente do tempo na escola. Não apenas por questões de estrutura, mas porque o ambiente e nível de atenção também mudam". ${ }^{5}$ Contudo, de que tempo e de que estrutura/espaço estamos falando?

De saída, importa dizer que as teorias pedagógicas trabalham com as categorias de tempo e espaço como noções estruturantes da escola e do currículo escolar. No entanto, para a vasta maioria dessas teorias, tempo e espaço constituem noções aproblemáticas, como se tivessem uma essencialidade e uma objetividade. A escola, com seus quadriculamentos e suas distribuições de espaços/tempos, obedece a uma lógica na qual o tempo e o espaço constituem coisas dadas, naturalizadas pelas rotinas, e escolares, deixando de ser questionadas como construtos históricos que se relacionam e estruturam a forma como percebemos o mundo e a nós mesmos. 
O momento atual é ainda mais delicado, porque saímos do espaço sólido a que estávamos acostumados, para experimentações dentro do ciberespaço, com o compromisso de mantermos os alunos no pique em que estavam, com o fim de garantir o funcionamento da escola e o pagamento das mensalidades. ${ }^{6}$

Importa frisar que as noções de tempo e espaço nas produções sociais são, a um só tempo, produtos e produtoras de poder. Nas palavras de Foucault,

[s]eria preciso fazer uma "história dos espaços" - que seria ao mesmo tempo uma "história dos poderes" - que estudasse desde as grandes estratégias da geopolítica até as pequenas táticas do habitat, da arquitetura institucional, da sala de aula ou da organização hospitalar, passando pelas implantações econômico-políticas. É surpreendente ver como o problema dos espaços levou tanto tempo para aparecer como problema histórico-político (1979, p. 211-212).

A insistência governamental em manter o calendário escolar, sob quaisquer condições, na perspectiva de que a carga horária mínima e os conteúdos básicos sejam devidamente cumpridos, tal como prescrito na Medida Provisória n. 934/2020 (BRASIL, 2020a), é devidamente frisada pelo Parecer CNE/CP n. 05/2020, quando chama a atenção das escolas para as avaliações externas, pois elas possuem o "foco nos conteúdos e objetivos de aprendizagem efetivamente cumpridos pelas escolas [...]" (BRASIL, 2020b). Diante da impossibilidade das aulas presenciais e das dificuldades em colocar em prática o ensino remoto, a escola pública alimenta o sonho de que a "normalidade" ou o "novo normal" aconteça o mais rapidamente possível e que os tempos/espaços disciplinares voltem a balizar suas rotinas. Por outro lado, vive o dilema de como propor espaços/tempos voltados aos objetivos de aprendizagem, demandados pelos controles externos, em pleno estado de calamidade pública. "Algumas dessas famílias que atendemos tiveram que receber nossa visita na porta de casa, pois nem contato telefônico foi possível"?

É notório que o acontecimento da Covid-19 exacerbou a visibilidade da ocorrência de novos regimes temporais/espaciais na contemporaneidade. Embora a escola pública continue estruturada e organizada pelos fundamentos da modernidade e suas crenças no sujeito epistêmico (universal, dotado de razão, idêntico) e na racionalidade científica (técnicas e métodos de ensino) como forma de garantia da aquisição dos conhecimentos escolares, o fato é que a pandemia fez tremularem com mais intensidade nossas certezas pedagógicas e ideais educativos, colocando sob suspeita os fundamentos que alicerçam as nossas compreensões sobre os espaços/tempos escolares, seus processos de escolarização e seus sujeitos.

Peter Pál Pelbart (2000), ao analisar a subjetividade contemporânea, vai argumentar que, mais do que criticar a noção de sujeito instaurada pela modernidade, caberia indagar que forças hoje circulam e reconfiguram as formas pelas quais atribuíamos sentidos às subjetividades. Pelbart recorre a Paul Virilio, filósofo francês do século XX, para dizer que "já não habitamos um lugar, mas a própria velocidade" (VIRILIO, 1977, apud PERBART, 2000, p. 12). Essas mudanças se dão pela confluência de três vetores: a rapidez absoluta, decorrente do progresso tecnocientífico, que reduziu as distâncias e, como consequência, contraiu o espaço e o tempo; o egotismo tecnológico resultante da perda dos referentes espaciais do mundo, da comunidade e de nós mesmos, que passamos a nos conceber "como espécies de aleijados rodeados de próteses tecnológicas por todos os lados, paralíticos entubados em meio à velocidade generalizada" (PERBART, 2000, p. 12); e a substituição de normas, regras e leis por uma espécie de telecomando universal e ondulatório.

Desde que as escolas tiveram suas atividades suspensas, o grande desafio é "virar a chave do mundo da sala de aula presencial para o universo digital". Entre os complicadores, as dificuldades de acesso às tecnologias por parte de estudantes e professores se agravam pela "falta de intimidade com essa nova realidade 
de uma parcela significativa de professores", o que faz com que "a busca por capacitações sobre o tema tenha aumentado". ${ }^{10}$ Não à toa as empresas que comercializam educação mediada por tecnologias apostaram pesado no marketing e colocaram à disposição dos(as) professores(as) cursos de capacitação do uso de diferentes ferramentas digitais engrossando o vigoroso caldo do e-commerce. As imagens vinculadas às ofertas de plataformas (todas “amigáveis") e aos cursos (sempre rápidos) de capacitação para a utilização de ferramentas digitais retratam profissionais felizes e confiantes para enfrentar os desafios dos "novos tempos".

Nesse cenário, a inclusão e a qualidade da educação básica passam a ser uma questão tecnológica. Logins e senhas demarcam permissões ou bloqueios de acesso. Por óbvio, diante dos bolsões de miséria presentes no Brasil e da crescente precarização das políticas públicas voltadas à democratização da educação, a maioria das crianças e dos jovens brasileiros fica à deriva enquanto as elites econômicas surfam nas ondas em escala global. Contudo, "para todo problema acreditamos que tenha uma solução. É hora de os professores colocarem a criatividade para funcionar, o que não pode é esse tempo longe da escola ficar ocioso e, mais tarde, tornar-se um problema e ficarem falhas no processo de aprendizagem". ${ }^{11}$ Prosseguindo, a reportagem mostra que, para garantir os objetivos do ensino, "professora coloca deveres em 'varal' para alunos não ficarem sem estudar [...]". ${ }^{12}$

Para além das velhas, e já bem conhecidas, condições precárias de infraestrutura das escolas públicas brasileiras, as novas paisagens escolares integram um cenário marcado pela instantaneidade (basta um clique!), acarretando o achatamento do tempo e do espaço e produzindo profundas alterações nas nossas experiências sensorial, perceptiva, cognitiva e existencial (PELBART, 2000). Esses fatores concorrem para o crescente mal-estar generalizado que vem sendo relatado pelas pessoas docentes: "Tenho tido ansiedade, picos de pressão. Já dei aula parando para vomitar por conta da hipertensão, dores de cabeça e das náuseas que tenho tido regularmente. Muita pressão de todos os lados." ${ }^{13}$

A mudança repentina nos modos de exercer a docência tem, provavelmente, tornado mais perceptível o redimensionamento das noções de tempo/espaço já presentes na nova engrenagem do poder social e que corresponde ao tipo de capitalismo ultraneoliberal que estamos vivendo. Como argumentaram Lazzarato e Negri "não é a tecnologia que impõe. Como disse Felix Guattari, é a máquina social que produz a máquina tecnológica” (2001).

Em termos de educação escolarizada, compreendemos que este período de cancelamento das aulas seja também um tempo de produção do estranhamento, do estremecimento das bases que sustentavam as instituições sociais nas disciplinas. Não que o poder disciplinar tenha deixado de se exercer, mas, nas sociedades de controle, ele foi flexibilizado. Trata-se de outra economia das relações de poder, segundo a qual a comunicação instantânea e o controle extravasam as instituições de reclusão e se estendem para o campo social onde a vida passa a ser controlada. Agora, o controle é feito de forma contínua (estamos, invariavelmente, necessitando de formação, reciclagem, aperfeiçoamentos) e atua por modulações que atravessam e regulam o tecido social. "Além da pressão do dia a dia para dar conta do processo, que é novo e trabalhoso, os professores ainda sofrem com ameaças de faltas e até processos administrativos caso não consigam trabalhar o conteúdo programado."14

A comunicação torna-se central para as sociedades de controle. Isso porque, como produto das relações sociais, ela atua diretamente na produção do trabalho imaterial, ou "trabalho afetivo" (PELBART, 2000, p. 39), que é base do novo modelo de produção. Ou seja, o trabalho imaterial não reproduz a exploração social, mas a reprodução de subjetividades (LAZZARATO; NEGRI, 2001). Esses processos são definidos pela relação que a produção estabelece entre seu mercado e seus consumidores.

A produção de nossos desejos, escolhas e condutas é feita nos e pelos fluxos capitalísticos instantâneos e constantes - de informações, imagens e serviços. “[...] as recentes mudanças evidenciam 
ainda mais a importância da comunicação como ponto estratégico nas instituições e na vida das pessoas, na atualização de notícias, informações em saúde, logística da vida diária, funcionamento de estabelecimentos, serviços públicos e, fundamentalmente, na rotina escolar." ${ }^{15}$

\section{Por um Currículo Xapiri}

No entanto, quando se diz o nome de um xapiri, não é apenas um espírito que se nomeia, é uma multidão de imagens semelhantes. Cada nome é único, mas os xapiri que designa são sem número [...]. Ficam vindo em nossa direção sem parar, acumulados em filas sem número. Suas imagens são as de todos os habitantes da floresta que descem do peito do céu, um depois do outro, com seus filhotes. As araras-vermelhas, amarelas e azuis, os tucanos, papagaios, jacamins, mutuns, cujubins, gaviões herama, wakoa e kopari, morcegos e urubus são muitos na floresta, não é? E os jabutis, tatus, antas, veados, jaguatiricas, onças-pintadas, suçuaranas, cutias, queixadas, macacos-aranha e guaribas, preguiças e tamanduás? E os pequenos peixes dos rios, poraquês, piranhas, peixes pintados kurito e arraias yamara aka, então? (KOPENAWA; ALBERT, 2015, p.116).

Diante das atuais paisagens sociais e pensando na perspectiva do currículo, cabe questionar: um currículo pode engendrar o espírito das florestas? Pode cantar, dançar, brincar, inventar, viver com e na pluralidade? Podemos educar para a potência em detrimento da obediência? O currículo pode ser xapiri?

Talvez mais interessante do que buscar respostas a esses questionamentos possa ser a possibilidade de problematizá-las no sentido de dar trabalho ao pensamento, até porque "as palavras determinam nosso pensamento porque não pensamos com pensamentos, mas com palavras, não pensamos a partir de uma suposta genialidade ou inteligência, mas a partir de nossas palavras" (BONDIA, 2002, p. 21). Também porque, como sabemos, os currículos escolares que temos, no geral, não dançam, não cantam, não inventam, não sonham... Eles obedecem! Obedecem a um conjunto normativo pesado (diretrizes, referenciais, BNCC, protocolos etc.). Acatam uma lógica espaço-temporal linear e sequencial. Submetem-se a composições hierarquizadas e homogeneizadas. Perseguem a formação do sujeito epistêmico e veneram as técnicas e as metodologias científicas como suportes que levarão à aquisição do conhecimento verdadeiro, inquestionável e universal.

Um currículo com esses atravessamentos definitivamente não é xapiri!

Propomos aqui pensar o currículo escolar orientada pelo conceito de agenciamento, proposto por Gilles Deleuze e Félix Guattari (1997), e buscamos identificar o que vem sendo dito sobre os currículos escolares em tempos de pandemia, além de como esses discursos constroem subjetividades e constituem sujeitos.

Entre os conceitos de dispositivo (criado por Foucault) e agenciamento (invenção de Deleuze e Guattari), existem ressonâncias e singularidades. No entanto, não é proposta deste artigo fazer esse exercício. Para os objetivos que aqui propomos, selecionamos uma passagem na qual Deleuze, ao comentar a obra de Michel Foucault, diz:

Não possuíamos o gosto pelas abstrações, o Uno, o Todo, a Razão, o Sujeito. Nossa tarefa era analisar estados mistos, agenciamentos, aquilo que Foucault chamava de dispositivos. Era preciso não remontar aos pontos, mas seguir e desemaranhar as linhas: uma cartografia, que implicava uma microanálise (o que Foucault chamava de microfísica do poder e Guattari, micropolítica do desejo). É nos agenciamentos que encontraríamos 
focos de unificação, nós de totalização, processos de subjetivação, sempre relativos, a serem sempre desfeitos a fim de seguirmos ainda mais longe uma linha agitada. Não buscaríamos origens, mesmo perdidas ou rasuradas, mas pegaríamos as coisas onde elas crescem, pelo meio: rachar as coisas, rachar as palavras. Não buscaríamos o eterno, ainda que fosse a eternidade do tempo, mas a formação do novo, a emergência, ou o que Foucault chamou de "a atualidade" (DELEUZE, 2006, p. 109).

Compreendemos que os dispositivos possam ser pensados como elementos constitutivos dos agenciamentos, pelo que utilizamos a compreensão foucaultiana do dispositivo para situar o ensino remoto emergencial como "um tipo de formação que, em um determinado momento histórico, tem (teve) como função principal responder a uma urgência. O dispositivo tem, portanto, uma função estratégica dominante" (FOUCAULT, 1979, p. 244). Foucault exemplifica essa função na emergência do dispositivo de controledominação da loucura, da doença mental e da neurose, diante de um sistema mercantilista que não tolerava essa população flutuante.

Acompanhando o entendimento de Foucault (1979), podemos dizer que o ensino remoto responde à urgência estratégica de manter os processos de educação institucionalizada de um contingente mundial de aproximadamente 800 milhões de jovens e crianças fora das salas de aulas e, portanto, desocupados. No Brasil, cerca de 56 milhões de alunos matriculados nas educações básica e superior tiveram as atividades presenciais suspensas, sendo que, desse universo, aproximadamente 48 milhões de estudantes frequentam a educação básica em uma das mais de 180 mil escolas brasileiras. ${ }^{16}$

Sobre a suspensão das aulas, a Unesco aconselhou os países a "aliviar o impacto sobre o currículo escolar de várias formas". ${ }^{17} \mathrm{O}$ primeiro passo é fazer uso o mais extensivo possível de todos os recursos a distância, seja pela Internet, seja por rádio ou televisão, bem como de todas as formas que permitam aprender e manter contato com a aprendizagem a distância. ${ }^{18}$ Considerando-se as cruéis e abismais desigualdades socioeconômicas brasileiras, o chamado ensino remoto emergencial, sem definição nos textos oficiais, passa a ser compreendido como "regimes especiais de ensino que compreendam atividades não presenciais mediadas ou não por tecnologias digitais de informação e comunicação", sendo que "a gestão do calendário e a forma de organização, realização ou reposição de atividades acadêmicas e escolares é de responsabilidade dos sistemas e redes ou instituições de ensino" (BRASIL, 2020b, p. 7).

Assim, caberá aos estados e municípios construírem guias de orientação para as comunidades escolares (famílias, estudantes, profissionais da educação) e protocolos sanitários que deverão considerar as singularidades locais. Nesse sentido, em que pese o respeito à autonomia dos entes federados em relação às definições de suas redes de ensino, é evidente que os efeitos perversos da agenda neoliberal e autoritária das políticas públicas em curso recairão sobre os estados e os municípios com maior concentração de populações periféricas, as quais são constituídas, em sua maioria, por pessoas negras, fortalecendo o racismo de Estado e a necropolítica.

Em termos de currículo, cabe lembrar que os textos legais insistem em grafar que a Base Nacional Comum Curricular (BNCC) não é currículo, desde suas versões iniciais, elaboradas pelo Ministério da Educação (MEC), em 2015. De acordo com o documento citado, a "Base deve nortear os currículos dos sistemas e redes de ensino das Unidades Federativas, como também as propostas pedagógicas de todas as escolas públicas e privadas de Educação Infantil, Ensino Fundamental e Ensino Médio, em todo o Brasil” (BRASIL, 2017). Logo, sem conceituação definida, o currículo passa a fazer parte de um discurso que o articula aos objetivos de aprendizagens, às propostas pedagógicas e às habilidades e competências previstas pela BNCC.

Essa estratégia discursiva ocupa a pauta das orientações prescritas à educação básica quando assinala que "a principal finalidade do processo educativo é o atendimento dos direitos e objetivos de aprendizagem previstos para cada etapa educacional, que estão expressos por meio das competências previstas na BNCC” 
(BRASIL 2020c. p. 6) e que podem ser "desdobrados nos currículos e propostas pedagógicas das instituições ou redes de ensino de educação básica" (BRASIL 2020c. p. 6). O Parecer CNE/CP n. 09/2020 admitiu a reorganização do Calendário Escolar em função da pandemia, abrindo a possibilidade de contabilizar carga horária para as atividades não presenciais. Sugere, inclusive, que "ciclos emergenciais" possam ser estabelecidos sem que haja a necessidade da segmentação anual, “desde que cumprida a carga horária mínima anual estabelecida nos referidos dispositivos, observadas as normas a serem editadas pelos respectivos sistemas de ensino" (BRASIL 2020c). As exceções ficam por conta do Ensino Médio e dos anos finais do Ensino Fundamental, que devem seguir o calendário letivo anual.

Identifica-se, nesse jogo discursivo, a ideia de que a educação, como direito de todos, deva ficar restrita à aquisição de habilidades e competências. Os conhecimentos - seleção, organização, distribuição, hierarquização -, problemáticas comuns aos estudos sobre os currículos, cedem lugar a uma lógica funcional, pragmática e mercadológica. A ênfase agora é na produção do sujeito bem-informado e, para tanto, “a comunicação é essencial neste processo" e "a BNCC é uma régua para detectar as defasagens e promover a garantia dos direitos de aprendizagem dos estudantes nos meses seguintes à retomada gradual das aulas presenciais" (BRASIL 2020c).

Embora tenha havido deslocamentos nas noções de tempo/espaço, decorrentes da suspensão das atividades na escola, manteve-se a obrigatoriedade de que as escolas cumpram com tempos lineares e cronológicos, prescritos pela legislação, bem como o dever de desenvolver os objetivos de aprendizagem e habilidades previstos na BNCC. Essas exigências são percebidas pelos(as) professores(as) como imposições que os(as) levam a "continuar trabalhando dentro daquilo que havia [havíamos] planejado para o semestre e também do material que a prefeitura está enviando às casas dos pequenos". ${ }^{19}$

O efeito bumerangue que estamos vivendo no campo da educação parece evidenciar o que, há mais de uma década, vem sendo tramado pelas políticas públicas a serviço da educação brasileira. Ou seja, trata-se de consolidar as bases do que Lazzarato e Negri (2001) chamam de capitalismo cognitivo, orientado pela gestão do capital humano. Já não se faz mais necessário educar os sujeitos pobres para aceitarem a exploração dos patrões. O próprio sujeito, empresário de si, torna-se explorador de si mesmo. Segundo o depoimento de uma professora: "Estabeleci uma meta diária de estudo e tenho refletido sobre a minha rotina de trabalho, repensado minha prática de sala de aula, acompanhado as novidades." 20

Muito provavelmente, a escola pública, tal como a conhecemos hoje, possa deixar de existir, dando lugar a empresas prestadoras de serviços educacionais, em geral, e de aquisição de competências específicas, em particular. Professores(as) e estudantes, consumidores ávidos, terão à disposição catálogos de produtos - sempre atuais e indispensáveis - destinados à satisfação profissional e à competitividade, que se acirrará entre nós na disputa por melhores lugares no mercado. Nesse cenário, é improvável que um currículo se deixe orientar pela força política da alegria, visto que "a alegria da invenção tem a ver com as novas formas de cooperação que ela enseja” (TARDE apud PELBART, 2000, p. 74).

Contudo, os currículos podem resistir, subverter, desconcertar e perturbar a ordem das coisas. Podem instaurar uma outra racionalidade aos processos de escolarização, colocando em perspectiva encontros inventivos, plurais e expansivos. É preciso remexer o "chão da escola”, revirar a terra e torná-la produtiva a encontros inventivos antes que seja definitivamente asfaltada. É possível mobilizar relações colaborativas que desenhem outras formas de sociabilidade, potencializadas pelo espírito da floresta. (...) Araras-vermelhas, amarelas e azuis, os tucanos, papagaios, jacamins, mutuns, cujubins, gaviões herama, wakoa e kopari, morcegos e urubus são muitos na floresta..." (KOPENAWA; ALBERT, 2015, p.116).

A pandemia da Covid-19 aguçou nossa percepção para o desajustamento do tempo/espaço e nos mostrou quão frágeis somos e o quanto dependemos da coletividade para continuarmos respirando. Talvez 
esse acontecimento possa estremecer o terreno árido ocupado pelas escolas, mobilizar seus currículos, agenciar outros saberes e produzir potências que constituam a alegria como função política da escola. "Quando se diz o nome de um xapiri, não é apenas um espírito que se nomeia, é uma multidão de imagens semelhantes”. Aciona-se a multidão (HARDT; NEGRI, 2005) como linhas de fuga, brechas, desobediências, potencias e multiplicidades. É preciso que o currículo combine, componha, conecte novas formas de relações e outros modos de produção, pois "a ação política voltada para a transformação e a libertação só pode ser conduzida hoje com base na multidão" (HARDT; NEGRI, 2005, p. 139). Em uma palavra, urge a necessidade de uma reviravolta curricular. Um movimento de deslocamento: da subordinação que se encontra à insubordinação, enquanto ainda é possível que paraquedas coloridos sejam criados e nos tirem dessa asfixia.

\section{Notas}

1. Referimo-nos, aqui, à pesquisa realizada pelo blog Nova Escola, "A Situação dos Professores na Pandemia", realizada entre os dias 16 e 28 de maio de 2020 por meio de um questionário on-line disponível no próprio site. Disponível em: https://novaescola.org.br/conteudo/19131/participe-da-pesquisa-nova-escola-sobre-a-situacaodos-professores-na-pandemia. Acesso em: 4 jun. 2020.

2. BRASIL..., 2014.

3. Aqui, referimo-nos à concepção de acontecimento proposta por Bárcena quando diz que: "El acontecimiento es, pues, uma irrupción imprevista en un estado de cosas que mantenía un decurso continuo y um transcurrir habitual. Es una fractura, una quiebra, una herida en el tiempo. Es lo discontinuo e im-previsto, lo que nos sorprende" (2004, p. 58).

4. Título de uma reportagem escrita pela Profa. Dra. Tatiana Lebedeff, veiculada pelo blog Desafios da Educação em 31 de março de 2020. Disponível em: https://desafiosdaeducacao.grupoa.com.br/volta-as-aulas-pos-coronavirus/. Acesso em: 9 jun. 2020.

5. Reportagem vinculada pelo blog Nova Escola, intitulada "Mudança de Rotina: Como se Manter Próximo das Famílias em Tempos de Pandemia”, em 28 de abril de 2020. Disponível em: https://novaescola.org.br/conteudo/19087/ mudanca-de-rotina-como-se-manter-proximo-das-familias-em-tempos-de-pandemia. Acesso em: 9 jul. 2020.

6. Depoimento de uma professora. Reportagem intitulada "Prática Docente: 30 Depoimentos sobre como a Escola foi Recebida em Casa”. Disponível em: https://desafiosdaeducacao.grupoa.com.br/depoimentos-sobre-escola-emcasa/. Acesso em: 4 maio 2020.

7. Ver nota n. 5.

8. Reportagem veiculada pelo blog Nova Escola, intitulada "Da Sala de Aula para a Internet: como a Pandemia do Coronavírus está Impactando as Escolas Públicas”, publicada em 2 de abril de 2020. Disponível em: https:// novaescola.org.br/conteudo/19006/da-sala-de-aula-para-a-internet-como-a-pandemia-do-coronavirus-estaimpactando-as-escolas-publicas. Acesso em: 4 maio 2020.

9. Ver nota n. 8 .

10. Ver nota n. 8 .

11. Reportagem veiculada em 7 de abril de 2020 pelo site Inovar - Educação de excelência - intitulada "O Ritmo das Escolas e a Pandemia Mundial do Novo Coronavírus". Disponível em: https://inovareducacaodeexcelencia.com/ blog/o-ritmo-das-escolas-e-a-pandemia-mundial-do-novo-coronavírus. Acesso em: 4 maio 2020. 
12. Ver nota n. 11 .

13. Reportagem divulgada por diferentes jornais e blogs baianos sob o título "Professores Revelam Bastidores de Educação a Distância”. Os dados divulgados se beneficiaram de uma pesquisa realizada pela Nova Escola, com o recorte para o estado da Bahia. Disponível em: https://www.anamt.org.br/portal/2020/07/13/professores-revelambastidores-de-educacao-a-distancia/. Acesso em: 9 jul. 2020.

14. Reportagem veiculada pela BBC News Brasil, em 11 de maio de 2020, intitulada "Ensino a Distância na Quarentena Esbarra na Realidade de Alunos e Professores da Rede Pública”. Disponível em: https://www.bbc.com/portuguese/ brasil-52568678. Acesso em: 7 jul. 2020.

15. Ver nota n. 14 .

16. BRASIL, $2020 \mathrm{~d}$.

17. Notícia veiculada pela Agência Brasil, em 13 de março de 2020, intitulada "Unesco: Covid-19 Deixa Mais de 776 Milhões de Alunos Fora da Escola”. Disponível em: https://agenciabrasil.ebc.com.br/internacional/noticia/2020-03/ unesco-covid-19-deixa-mais-de-776-milhoes-de-alunos-fora-da-escola. Acesso em: 6 jul. 2020.

18. Ver nota n. 17 .

19. Ver nota n. 5 .

20. Ver nota n. 6 .

\section{Referências}

ARANHA, M. L. A. História da educação e da pedagogia geral e Brasil. 3. ed. São Paulo: Moderna, 2006. ARIÈS, P. História social da criança e da família. Rio de Janeiro: Zahar, 1986.

BÁRCENA, F. El delirio de las palabras. Ensayo para una poética del comienzo. Barcelona: Herder, 2004. BONDIA, J. L. Notas sobre a experiência e o saber de experiência. Revista Brasileira de Educação, Rio de Janeiro, n. 19, p. 20-28, 2002. https://doi.org/10.1590/S1413-24782002000100003

BRASIL. Base Nacional Comum Curricular. Brasília, DF: MEC, 2017. Disponível em: http:// basenacionalcomum.mec.gov.br/images/BNCC_20dez_site.pdf. Acesso em: 22 dez. 2017.

BRASIL. Medida Provisória n. 934, de $1^{\circ}$ de abril de 2020. Estabelece normas excepcionais sobre o ano letivo da educação básica e do Ensino Superior decorrentes das medidas para enfrentamento da situação de emergência de saúde pública de que trata a Lei n. 13.979, de 6 de fevereiro de 2020. Brasília, DF: Presidência da República, 2020a. Disponível em: https://abmes.org.br/arquivos/legislacoes/Medidaprovisoria-934-2020-04-01.pdf. Acesso em: 8 jul. 2020.

BRASIL. Parecer CNE/CP n. 5, de $1^{\circ}$ de junho de 2020. Reorganiza o Calendário Escolar e da possibilidade de cômputo de atividades não presenciais para fins de cumprimento da carga horária mínima anual, em razão da Pandemia da COVID-19. Brasília, DF: MEC, 2020b. Disponível em: http://portal.mec.gov.br/ index.php?option=com_docman\&view=download\&alias=145011-pcp005-20\&category_slug=marco-2020pdf\&Itemid=30192. Acesso em: 1 jul. 2020. 
BRASIL. Parecer CNE/CP n. 9, de 8 de junho de 2020. Reexamina o Parecer CNE/CP n. 5/2020, que tratou da reorganização do Calendário Escolar e da possibilidade de cômputo de atividades não presenciais para fins de cumprimento da carga horária mínima anual, em razão da Pandemia da COVID-19. Brasília, DF: MEC, 2020c. Disponível em: http://portal.mec.gov.br/index.php?option=com_docman\&view=download\&alias =147041-pcp009-20\&category_slug=junho-2020-pdf\&Itemid=30192. Acesso em: 1 jul. 2020.

BRASIL. Secretaria da Transparência. Educação durante a pandemia. Brasília, DF: Instituto de Pesquisa DataSenado, ago. 2020d. Disponível em: https://www12.senado.leg.br/institucional/datasenado/publicacoe sportema?tema=Covid-19. Acesso em: 10 ago. 2020.

BRASIL lidera ranking de violência contra professor. Agência Câmara de Notícias, 15 out. 2014. Disponível em: https://www.camara.leg.br/noticias/443123-brasil-lidera-ranking-de-violencia-contra-professores/. Acesso em: 9 jul. 2020.

DELEUZE, G. Post-scriptum: sobre as sociedades de controle. Conversações. Rio de Janeiro: Editora 34, 1992.

DELEUZE, G. Conversações. Rio de Janeiro: Editora 34, 2006.

DELEUZE, G., GUATTARI, F. Mil platôs: capitalismo e esquizofrenia. Rio de Janeiro: Editora 34, 1997. v. 1. FOUCAULT, M. Microfísica do poder. Rio de Janeiro: Graal, 1979.

FOUCAULT, M. A arqueologia do saber. Rio de Janeiro: Forense Universitária, 1986.

FOUCAULT, M. Dits et écrits. Paris: Gallimard, 1994. v. IV.

FOUCAULT, M. A verdade e as formas jurídicas. 4. ed. Rio de Janeiro: Nau, 2013a.

FOUCAULT, M. Vigiar e punir. Petrópolis, Rio de Janeiro: Vozes, $2013 \mathrm{~b}$.

HARDT, M.; NEGRI, A. Multidão: guerra e democracia na era do império. Rio de Janeiro: Record, 2005.

KOPENAWA, D; ALBERT, B. A queda do céu: palavras de um xamã Yanomami. São Paulo: Companhia das Letras, 2015.

KRENAK, A. Ideias para adiar o fim do mundo. São Paulo: Companhia das Letras, 2019.

LAZZARATO, M.; NEGRI, A. Trabalho imaterial: formas de vida e produção de subjetividade. Rio de Janeiro: DP\&A, 2001.

MBEMBE, A. Pandemia democratizou poder de matar. Entrevista concedida a Diogo Bercito. Folha de S. Paulo, 30 mar. 2020. Disponível em: https://www1.folha.uol.com.br/mundo/2020/03/pandemiademocratizou-poder-de-matar-diz-autor-da-teoria-da-necropolitica.shtml. Acesso em: 7 maio 2020.

PELBART, P. P. Vertigem por um fio: políticas da subjetividade contemporânea. São Paulo: Iluminuras, 2000.

VARELA, J. O estatuto do saber pedagógico. In: SILVA, T. T. (org.). O sujeito da educação: estudos foucaultianos. Petrópolis: Vozes, 1994. p. 87-96.

VARELA, J.; ALVAREZ-URÍA, F. A maquinaria escolar. Teoria \& Educação, São Paulo, n. 6, p. 68-96, 1992. 


\section{Sobre a Autora}

Eliana Póvoas Pereira Estrela Brito é pedagoga com Doutorado em Educação pela Universidade Federal do Rio Grande do Sul (UFRGS). Professora permanente do Programa de Pós-graduação em Estado e Sociedade (PPGES) da Universidade Federal do Sul da Bahia (UFSB) e do Programa de Pós-graduação em Ensino e Relações Étnico-Raciais da mesma instituição (PPGER/UFSB). Pesquisa temas que envolvam currículo, cultura e diferenças.

Recebido: 25 ago. 2020

Aceito: 11 maio 2021 